\title{
Living with Internet Addiction: Experience of Adolescent Girls during Learning from Home in COVID-19 Pandemic
}

\author{
Suryani Suryani ${ }^{1}$ *, Windy Rakhmawati ${ }^{2}$, Restuning Widiasih ${ }^{3}$, Cecep Eli Kosasih ${ }^{4}$ \\ ${ }^{1}$ Department of Mental Health Nursing, Faculty of Nursing, Universitas Padjadjaran, Bandung, Indonesia; ${ }^{2}$ Department of \\ Pediatric Nursing, Faculty of Nursing, Universitas Padjadjaran, Bandung, Indonesia; ${ }^{3}$ Department of Maternity Nursing, Faculty \\ of Nursing, Universitas Padjadjaran, Bandung, Indonesia; ${ }^{4}$ Department of Critical Nursing, Faculty of Nursing, Universitas \\ Padjadjaran, Bandung, Indonesia
}

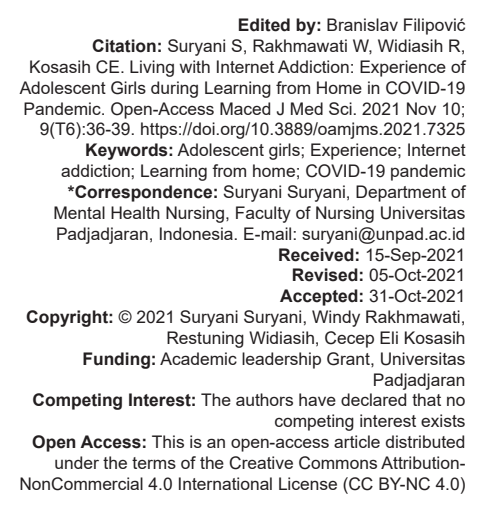

Introduction

In the era of the 4.0 industrial revolution, the internet has become the main mean of communication due to its easy and rapid connection. The number of internet users tends to increase from year to year, as internet simplifies many aspects of life. By the end of 2020 , the number of internet users has reached $7,875,765,584$ [1], with $54.9 \%$ of them are from the Asian continent, contributing the largest number of internet users in the world. In Indonesia, the number of internet users has reached $196,400,000$ in 2020 or around $71.1 \%$ of the total population of Indonesia [1]. Adolescents have not developed the ability to sort out which internet activities or contents are beneficial for them and which ones are not. They tend to be easily influenced by their friends or peers on social media without considering the positive or negative effects of certain internet activities.

There are lots of benefits of internet use for adolescents, such as for their learning activities in school, especially during the COVID-19 pandemic when adolescents have to learn from home. However, excessive internet use can have negative impacts on these adolescents. Examples of such impacts are excessive internet use or online game play; inability to complete tasks, and lack of ability to form social connection in the real world [2], [3]. A study conducted in Iran by Alavi et al. (2011) suggested that adolescents with internet addiction have a higher tendency tend to show symptoms of psychological [4].

Nurses as health workers are responsible for improving a person's health status, both physically and mentally; thus, nurses should be involved in managing internet addiction in individuals and society. Nurses can encourage parents and teachers to identify internet addition in their children and students and assist the children or students in their online learning activities to reduce the negative impacts of internet use. Nurses can also be involved in preventing and overcoming internet addiction problems in adults and in society at large.

To be able to develop appropriate interventions and find solutions to prevent internet addiction in 
adolescents, a comprehensive understanding of what, how, and why Indonesian adolescents, especially adolescents in West Java, experience internet addiction needs to be understood. This study aimed to explore the experience of internet addiction among teenage girls in West Java as well as a need assessment for required interventions for this phenomenon.

\section{Methods}

This qualitative study applied the
phenomenology approach.

\section{Participants}

The participants in this study were high school students from high schools in Bandung, Cirebon, Purwakarta, and Sukabumi area of West Java Province, Indonesia. The inclusion criteria for this study were high school students from high schools; experienced moderate internet addition as evidenced by the result of the Internet Addiction Test; [5] and able to communicate in Indonesian. Exclusion criteria were participants with communication problem and psychiatric disorders such as depression and schizophrenia. Thirteen participants were considered to meet the criteria by purposive sampling technique.

\section{Data collection}

Selected participants for in-depth interviews were contacted through WhatsApp chat. The interviews were conducted by three sessions of video call: The first one lasted for $30 \mathrm{~min}$ to build a trusting relationship and signing informed consent and contract for the interview sessions. The second interview took $1 \mathrm{~h}$ to explore the participants' experiences related to internet use and internet addiction while the third one, which also took $1 \mathrm{~h}$, aimed to validate the results of the previous interview. All participants were able to describe detailed experiences related to internet use and internet addiction and finished the three interview sessions.

\section{Data analysis}

Data were analyzed using the Colaizzi method with seven stages of analysis [6].

\section{Ethical consideration}

The study was approved by Health Commission Ethic from Faculty of Medicine, Universitas Padjadjaran, Indonesia, with number 465/UN6.KEP/EC/2020 on May 7, 2020.

\section{Results}

We found five themes consist of (1) constant use of the internet due to boredom, lack of things to do, bad mood, and curiosity; (2) health issues due to internet use; (3) easily influenced by internet contents; (4) tend to forget learning materials and lazy to learn; and (5) parental supervision.

Theme 1: Constant use of internet due to boredom, bad mood, and curiosity

This theme was expressed by most of the participants and supported by two subthemes as presented below.

\section{Constant use of internet due to boredom and bad mood}

Many of the participants used the internet constantly because they felt bored with their learning activities during the pandemic as articulated by a participant:

"I use the internet when I'm bored, Ma'am. You see, it is so boring nowadays. When I'm bored, I read people's stories" (APC, 18 years old).

\section{Constant use of internet out of curiosity}

In addition to feeling bored, "gabut," and bad mood, the participants also constantly accessed the internet, especially social media, out of curiosity, as expressed by one of the participants in this study. "I'm curious, Ma'am, what content do they post today. I'm really curious about my friends' status updates... because they update (their status) frequently" (CTK, 17 years old).

\section{Theme 2: Health issues due to internet use}

Prolonged internet use is already known as causing various health issues. This was also mentioned by the participants. The main health issues experienced by the participants were those related to the eyes. Almost all participants stated that their eyes hurt when using the internet for too long. Other health problems mentioned were dizziness, muscle aches, back pain, and sleep disorders.

One of the participants, SF, revealed that she experienced problem with her eyes due to prolonged use of the internet: "The first impact is on the eyes, Ma'am, (and) the second is that we become addicted to the internet" (SF, 17 years old).

In addition to the impact on the eyes and dizziness, one participant also mentioned stiff muscles as the health issue experienced due to internet use. 
"My body feels so sore... it makes me feel lazy to do anything. Once... my eyes got red... then I stopped playing with the cellphone... I slept all night... then I felt better after that. Once, Ma'am ... my back was so painful... felt like I was having a cold" (ARS, 19 years old).

\section{contents}

Theme 3: Easily influenced by internet

In general, teenage girls experience some level of dependence on social media. They are always interested in checking out new information or new status updates from their friends or their idols. The negative impact is that they are also easily influenced by what they see on social media, as stated by the participants:

"The psychological impact I feel most is that sometimes, what I see... when I see an Insta story about someone's being on vacation, I indirectly want to have and enjoy a vacation too. Seems that if I don't follow the trend, it will feel less inspired, Ma'am" (CD, 17 years old).

\section{and lazy to learn \\ Theme 4: Tend to forget learning materials}

Based on the results of the study, it was revealed that almost half of the participants stated that due to their deep interest into the internet, especially social media, they became lazy to learn and tended to forget about the lessons they had learned.

"For me personally, it's easy to forget. For example, I just finished studying and then I opened social media, then the lessons I read earlier, I usually already forget (about it)" (SF, 17 years old).

\section{Theme 5: Parental supervision}

Prolonged use of the internet and the tendency of adolescents to be easily influenced by what they see on social media make parental supervision important, as expressed by one of the participants:

"My message to parents is that (they should) monitor their children more intensively, monitor their children's development... continue to cooperate with teachers at school... especially for adolescents whose interactions are sometimes unbelievable. I have experienced it... that's how it is, Ma'ams" (SF, 17 years old).

\section{Discussion}

Adolescence is a transitional period from childhood to adulthood. Adolescents tend to be very active in search for their self-identity. The internet use is very high in this age group, amounting to $79.5 \%$ [7]. The use of the internet in adolescents has a lot of influence on their mental and personality development.

In this study, the first theme identified was constant use of the internet due to boredom, lack of things to do, bad mood, and curiosity. The feeling of boredom arises because the participants had to study on their own during the COVID-19 pandemic. After they finish with their learning, they feel that they have no further activities or lack of things to do, do not know what they are supposed to do with their time so they play with the internet. This constant use of the internet is also triggered by their curiosity about the stories or posts made by their friends and their idols. This "gabut" state, boredom, and curiosity trigger these girls to constantly access social media, increasing their use of the internet. They become lost in time and forget their main duties as students. This supports the finding of a previous study by Suryani, Sriati, and Septiani (2020) where their participants stated that playing with the internet is more important than school [3].

This situation should raise concerns among parents, school, and the government to do various efforts to make adolescents always active and have lots of activities. Of course, the activities should be those that they enjoy and these activities should be done in the real world, not through cyberspace. At present, there are many activities carried out by adolescents; however, most of these activities are performed in cyberspace, such as creating contents for TikTok and YouTube. These activities can also develop their creativity but they do not make them physically and socially active. Adolescents must be physically active. Adolescents who are physically active have been shown to have less sleep disturbances, stress, and excessive internet use [8], [9]. Adolescents also need to be active socially. With more time spent in the cyberspace, they only have little time for social relationships. This has been proven to make these adolescents find it difficult to empathize and unable to carry out social interactions well [3]. Social activities can increase various competencies such as empathy, emotional control, socially acceptable ways of interactions, and so on [10].

Another theme identified was health issues. Adolescent girls in this study reported that they experienced various health problems such as eye sore, head spinning, red eyes, blurry vision, dizziness, aching muscles, sleep pattern disturbance, and difficulty in sleeping. Constant and prolonged exposure to radiation rays from cellphones clearly causes damages to the eyes [11]. Another physical effect of prolonged use of the internet is body and muscle aches that stem from lack of physical activities and staying in lying position for a long time while playing with cellphones, preventing the blood to flow smoothly to all parts of the body. This condition, if not addressed immediately, can affect the overall health of adolescents. 
Because they are too engrossed in social media, almost all participants stated that they easily forget lessons and are lazy to learn. When on social media, they really enjoy their activities and they are become absorbed in the contents of the social media that do not need so much efforts to follow. This is in contrast to learning which tends to require full thinking capacity and concentration to understand the subject. As a result, they spend more time on social media than on studying. Contents that influence the adolescent mindset do not only relate to the easy ways to earn money that affect the perspective of adolescents regarding how they can live independently in the future. Many other things that they find on the internet can also affect their attitudes and behaviors, such as contents on lifestyle, dating, and so on.

Participants in this study admitted that their excessive use of the internet is due to the lack of monitoring from parents and peers' influence. The cause of internet addition is due to lack of parental supervision [12], poor communication patterns between parents and child [12], [13], and more attach with peers than with parents [14]. Therefore, parents should control their children's internet use and regularly check the contents accessed by their children on social media, as well as their children's interactions on the internet [12]. Besides, parents also have to maintain attachment and good communication with their children.

It is impossible for parents to supervise their children internet use $24 \mathrm{~h}$ a day, 7 days a week. Therefore, the government's role is important to ease the burden of parents in supervising their children's use of internet. Government can apply regulations and policies that ensure the appropriate use of internet for children and adolescents. In movies, there is already a rule on which movies are for children and which movies can only be watched by those who are already 17 years old or above. Now, a similar regulation should be imposed to prevent underage children to use social media such as Instagram, Line, TikTok, Facebook, and so on.

\section{Conclusion}

Five themes have been identified in this phenomenology study: Constant use of the internet due to boredom, lack of things to do, bad mood, and curiosity; health issues due to internet use; easily influenced by internet contents; tend to forget learning materials and lazy to learn; and parental supervision. These themes can be used as considerations when developing internet addiction prevention and intervention programs for adolescent girls, as well as for subsequent research.

\section{References}

1. Stats IW. World Internet usage and Population Statistic; 2020. Available from: https://www.internetworldstats.com/stats.htm. [Last accessed on 2021 Oct 12].

2. Yang SC, Tung CJ. Comparison of Internet addicts and nonaddicts in Taiwanese high school. Comput Human Behav. 2007;23(1):79-96. https://doi.org/10.1016/j.chb.2004.03.037

3. Suryani S, Sriati A, Septiani N. Lived experiences of adolescents with internet addiction. Nurse Media J Nurs. 2020;10(2):158-70. https://doi.org/10.14710/nmjn.v10i2.31161

4. Alavi SS, Maracy MR, Jannatifard F, Eslami M. The effect of psychiatric symptoms on the internet addiction disorder in Isfahan's University students. J Res Med Sci. 2011;16(6):793-800. PMid:22091309

5. Young K. Internet Addiction Test (IAT). Illinois, United States: Stoelting; 2016.

6. Morrow R, Rodriguez A, King N. Colaizzi's descriptive phenomenological method. Psychologist. 2015;28(8):643-4.

7. IM of $\mathrm{C}$ and Information, 98 Persen Anak dan Remaja Tahu Internet; 2020.

8. Park S. Associations of physical activity with sleep satisfaction, perceived stress, and problematic internet use in Korean adolescents. BMC Public Health. 2014;14(1):1143. https://doi. org/10.1186/1471-2458-14-1143

PMid:25373558

9. Kusnanto K, Rohmah FA, Wahyudi AS, Arifin H. Mental workload and stress with blood glucose level: A correlational study among lecturers who are structural officers at the university. Syst Rev Pharm. 2020;11(7):253-7.

10. Malik F, Marwaha R. Developmental Stages of Social Emotiona Development in Children. Treasure Island, FL: Stat Pearls; 2020.

11. Moon JH, Kim KW, Moon NJ. Smartphone use is a risk factor for pediatric dry eye disease according to region and age: A case control study. BMC Ophthalmol. 2016;16(1):188. https://doi. org/10.1186/s12886-016-0364-4 PMid:27788672

12. Tajalli F, Zarnaghash M. Effect of family communication patterns on internet addiction. Pract Clin Psychol. 2017;5(3):159-66.

13. Lin $\mathrm{CH}$, Lin SL, Wu CP. The effects of parental monitoring and leisure boredom on adolescents' internet addiction. Adolescence. 2009;44(176):993-1004. PMid:20432612

14. Ariani P, Suryani S, Hernawaty T. Relationship between academic stress, family and peer attachment with internet addiction in adolescents. J Keperawatan Padjadjaran. 2018;6(3):215-26. https://doi.org/10.24198/jkp.v6i3.483 